\title{
Pollution and the choice of where to work and live within Mexico City
}

\author{
Matías Fontenla ${ }^{1}$, M. Ben Goodwin ${ }^{1 *}$ (D) and Fidel Gonzalez ${ }^{2}$
}

*Correspondence:

mbengoodwin@unm.edu

${ }^{1}$ Department of Economics,

University of New Mexico,

Albuquerque, NM 87131, USA

Full list of author information

is available at the end of the article

\begin{abstract}
Global air pollution continues to increase across the world, and Mexico City is one of the most polluted cities in the western hemisphere. This paper considers the tradeoff between wages, housing characteristics, and air quality in the conjoint decision of where a household decides to live and work. We estimate compensating differentials using a three-stage least squares (3SLS) instrumental variable approach that accounts for the simultaneous nature of the housing and wage markets. To address endogeneity, we capitalize on the localized relationship between air pollution and rainfall. We assemble a dataset for Mexico City which includes the actual transacted value of the house, house features, household socioeconomic characteristics, particulate matter pollution (PM10) concentrations, and rainfall. Our results indicate that the average household needs to be compensated by approximately US\$1007.54 per year to tolerate a $1 \mathrm{\mu g} / \mathrm{m}^{3}$ increase in PM10. Our estimates are on the higher end of previous studies. If estimates under-represent the value of clean air, then this discourages government policy aimed at mitigating pollution, with all its health and quality of life implications.
\end{abstract}

Keywords: Particulate matter (PM10), Valuation of air quality, Wage-hedonic models, Residential sorting, Compensating differential, Marginal willingness to pay, Mexico, Latin America

JEL Classification: O1, Q5, R2

\section{Introduction}

The negative health and quality of life implications of pollution have been extensively documented. Nevertheless, global air pollution continues to rise, with an $8 \%$ increase in world pollution levels from 2007 to 2013 . Virtually, all of the most polluted cities are in the developing world, with $98 \%$ of cities in developing countries experiencing unsafe exposure levels at some point. In these cities, air quality regulations often take a back seat to other priorities. Mexico City exemplifies this problem with over 22 million inhabitants living in one of the most polluted cities in the western hemisphere (WHO 2014).

Arguably, the two largest and most important market choices individuals make are where to work and live. Theory suggests that a disamenity such as air pollution is tied into these markets as individuals jointly make labor and housing decisions, considering the attributes of a local area. As air pollution is universally perceived as detrimental to quality of life, individuals may require to be compensated, either through higher wages or lower housing prices, to live in areas with lower air quality.

(c) The Author(s) 2019. This article is distributed under the terms of the Creative Commons Attribution 4.0 International License (http://creativecommons.org/licenses/by/4.0/), which permits unrestricted use, distribution, and reproduction in any medium, provided you give appropriate credit to the original author(s) and the source, provide a link to the Creative Commons license, and indicate if changes were made. 
Mexico City provides a unique opportunity to help understand the relationship between pollution, labor, and housing markets within a single city in a developing country. It has a large middle-class population that has the ability and flexibility to make decisions within the labor and housing markets. In addition, plagued by chaotic traffic, households may choose to live closer to their employment to eliminate long commutes.

With its unique topography, Mexico City sits at the bottom of a bowl surrounded by mountains, trapping particulate matter and other pollutants. Further, low winds, its tropical location, elevations over $2200 \mathrm{~m}$ (7300 feet), a large population, industry, and an aging fleet of vehicles all combine to create high levels of pollution.

In this study, we measure the value of clean air to the residents of Mexico City captured by housing and labor markets. We estimate the compensating differential for individuals to tolerate air pollution using a dual-sorting hedonic model as initially developed by Roback (1982). We take into account the interconnection between housing and labor markets along with the local amenities offered within neighborhoods. We focus on the detrimental amenity of air pollution in the form of particulate matter $10 \mu \mathrm{m}$ or less in diameter (PM10). This is the most visible air pollutant measurement and has the greatest impact on people's perception of pollution levels (WHO 2014).

We assemble a rich dataset that is rarely available for a developing country. We combine environmental data from various agencies and use GIS to link it to individual home sales and wages of the buyers. Our dataset contains information on the actual transacted price of the home, physical characteristics of the housing unit, and socioeconomic information of the household purchasing the home. We merge this information with the neighborhood's hourly PM10 readings and daily rainfall to analyze the simultaneous impact of PM10 concentrations on housing prices and income. While previous work looks at aggregate data and average home values across cities, our unique dataset allows us to focus at the individual house level within a city, which greatly alleviates the problem of migration, distances, and information costs.

Our paper undertakes a simultaneous equation three-stage least squares (3SLS) instrumental variable approach that accounts for endogeneity and omitted variable bias. The system of equations allows us to account for the suspected correlation of the disturbances between the equations. We also use location fixed effects at the postal code level to address for time unvarying variables and minimize the impacts of spatial autocorrelation.

In Mexico City, we find that PM10 can be strongly instrumented by rainfall. Rain scrubs air pollution from the atmosphere through the process of wet deposition (Barmpadimos et al. 2011). While rain can be considered an amenity that affects the choice of where to work and live, it should not be a concern in our case. Country-level studies that compare cities across large distances, such as the U.S., may present large precipitation variations that can influence household's decisions on where to live. Our study, however, focuses on a single city without the large variations in rainfall that may impact these decisions. Further, if rain acts as an amenity in itself, it would have an opposite effect on pollution. High rain would be considered a negative amenity in an urban setting, whereas it has a positive effect on air quality. If this is the case, our estimates would provide a lower bound of the effects of air pollution on housing prices and incomes. 
Another potential concern is that rain variations could affect wages through agricultural yields. However, this is not an issue in our paper, as there is no agriculture in our urban setting. We further alleviate these concerns by including zip code fixed effects and additional controls in all of our regressions.

Our results suggest that the residents of Mexico City are compensated for higher pollution levels through both the labor and housing markets. Our estimates show that the elasticity between pollution and house prices is -0.30 and the wage elasticity equals 1.60. These results translate into an average household needing to be compensated by US\$ 83.96 , or $2.98 \%$ of average income per month to accept a $1 \mu \mathrm{g} / \mathrm{m}^{3}$ increase in average PM10 levels.

As with any hedonic work, we caution extending these estimates beyond our geographic area of study. Further, comparing our results with other studies should be done with care, as different data, time-frames, methodologies, and outcomes measured may render different and hard to compare results.

With this caveat, our results are roughly on the higher end relative to studies in both developed and developing nations. For Mexico, Rodriguez-Sanchez (2014) replicates the Bayer et al. (2009) two-stage hedonic model that accounts for migration costs within Mexico, estimating an annual willingness to pay (WTP) between US\$ 46.90 and 283.61. Gonzalez et al. (2013) use similar data to ours for Mexico City, Guadalajara and Monterrey, and calculate a marginal willingness to pay (MWTP) for housing values in the range of US\$36.34 to 43.47. Filippini and Martinez-Cruz (2016) use a contingent valuation survey in a high-pollution municipality within Mexico City and find an average WTP of US\$ 262 per respondent. Chakraborti et al. (2019) estimate land values within Mexico City and find a marginal WTP of US\$231.77 per average land parcel. For Chile, Lavín et al. (2011) estimate an inter-city hedonic approach that includes both the housing and labor markets, and find a monthly value of a marginal improvement in air quality between US\$ 3 and 6. Carriazo and Gomez-Mahecha (2018) construct a demand function for air quality in Bogotá, Colombia, and estimate a willingness to pay of US\$12.16 per month per household.

While the unique elements of each study do not allow for a direct comparison, our actual housing transaction and household-level data should provide more precise estimates relative to previous studies that rely on average city-level housing prices and wages. Estimates of the value of air quality are of great practical interest to policy makers. If estimates under-represent the value of clean air, then this discourages government policy aimed at mitigating pollution, with all its health and quality of life implications.

\section{Theoretical framework}

Our theoretical framework closely follows Roback (1982) dual-sorting model to estimate the full implicit price of clean air in Mexico City. The model is based on the idea that local amenities of an area will be capitalized in both the housing and wage markets. Variations of this model have been used to calculate compensating differentials in labor and housing markets for large-scale amenities at the inter-regional level. ${ }^{1}$ One notable

\footnotetext{
${ }^{1}$ See, for example Berger et al. (2008), Izon et al. (2010), Lavín et al. (2011), and Huang and Lanz (2018)
} 
difference is that previous work utilizes inter-city differences, while we are able to focus at the individual household level within a city. This reduces potential bias associated with neglecting migration and information costs which likely increase with distance, as demonstrated by Bayer et al. (2009). Summarizing Roback's model, we consider an individual that maximizes utility based on the following problem:

$$
\max _{h, x . \phi} U=f(h, x ; \phi) \text { s.t. } w=x+h r .
$$

The utility of the household depends on the quantity consumed of housing, $h$, the composite good $x$ and air pollution, $\phi$, which is the local amenity of interest. The household's budget constraint shows that income or wages $w$ is equal to expenditure in the composite good consumption plus housing. The price of the composite good is normalized to one. The price per unit of housing is $r$.

Theory suggests that for a household to be indifferent between two locations, consumption levels of other goods must adjust to compensate for changes in a particular amenity. Since the budget constraint is binding, to alter consumption and remain at the same utility levels, wages and housing prices must adjust to remain in equilibrium. This is shown through the indirect utility function: $\bar{V}=V(w, r ; \phi)$, where $\bar{V}$ is the maximized level of utility. The marginal utilities are determined by their partial derivatives, with $V_{w}>0, V_{r}<0$, and $V_{\phi}<0 .^{2}$

As wages are also based on decisions by firms, we need to consider their profit maximization decisions. Using the dual property between profit maximization and cost minimization, the location decision of the firm can be captured by the cost function. Setting the price of the composite good equal to one, the unit cost function of the firms is expressed as $C(w, r ; \phi)=1$, with $C_{w}>0$ and $C_{r}>0$. Intuitively, increases in either factor, wages or rental prices, increases costs for the firm. If air pollution is purely a consumption amenity and does not affect production, then $C_{\phi}=0$.

In equilibrium, wage and housing prices are determined by the decisions individuals and firms make on location choices, which inherently include the local amenities of each area. Firms may recognize that air pollution as a disamenity for workers and may have to compensate them through higher wages. By taking the total differential of indirect utility and cost function, we obtain the expression that shows the effect of air pollution in wages and housing prices:

$$
\begin{gathered}
\frac{\partial w}{\partial \phi}=\frac{1}{\Pi}\left(-V_{\phi} C_{r}+C_{\phi} V_{r}\right), \\
\frac{\partial r}{\partial \phi}=\frac{1}{\Pi}\left(-V_{w} C_{\phi}+V_{\phi} C_{w}\right),
\end{gathered}
$$

with $\Pi=\left(V_{w} C_{r}-V_{r} C_{w}\right)>0$. If air pollution does not affect production (i.e., a consumption amenity only) then $w_{\phi}>0$ and $r_{\phi}<0$, and higher air pollution leads to higher wages and lower housing prices.

\footnotetext{
${ }^{2}$ Partial derivatives of the indirect utility and the unit cost functions are shown by a subscript on the main variable of interest, as in $\frac{\partial V}{\partial w}=V_{w}$
} 
Next, we obtain the expression for the full implicit price of air pollution or compensating differential, $\varphi^{*}$, by taking the total derivative of the indirect utility function and using Roy's identity:

$$
\varphi^{*}=-h \frac{\partial r}{\partial \phi}+\frac{\partial w}{\partial \phi} .
$$

The compensating differential, $\phi^{\prime \prime}$, is the effect that changes in air pollution have on additional housing $\operatorname{costs}\left(h \frac{\partial r}{\partial \phi}\right)$ plus the compensating increases in wages $\frac{\partial w}{\partial \phi}$. The sum of these two effects can be considered as the total monetary compensation needed to endure a marginal change in pollution levels.

As demonstrated in other hedonic studies, obtaining consistent unbiased estimations of hedonic prices can often be difficult due to unobserved covarying factors associated with pollution, housing prices, and wages. For example, house prices may actually be higher in areas with lower air quality when they are in more urbanized sections, demonstrating an omitted variable bias. This was illustrated in Smith and Huang (1995) who showed that around a fourth of the 86 different estimates of willingness to pay to reduce air pollution from 37 different studies between 1967 and 1988 actually showed counterintuitive results. In other words, results suggested there was a positive relationship between house prices and air pollution levels. Similarly, Zabel and Kiel (2000) found only 19 of 80 estimated coefficients exhibiting the expected negative sign for a number of pollutants across the US. Finally, many estimates in early air pollution hedonic studies were not statistically significant, suggesting a bias towards zero ( $\mathrm{Li}$ and Brown 1980, Palmquist 1982). We address the omitted variable bias and the simultaneity aspect of the decision to accept wages and buy a house using an instrumental variable, simultaneous estimation approach.

\section{Data and study area}

Our analysis focuses on the greater urban area of Mexico City, which spans the Federal District and parts of the surrounding State of Mexico. The main dataset includes 1546 individual house sales during the January 2003 to May 2004 timeframe. We combine this with pollution data in the form of PM10 obtained from monitoring stations throughout the city. Finally, as detailed below, we use precipitation as an instrument for pollution. Figure 1 shows the extent of the area of study including the spatial distribution of house transactions, pollution monitoring stations, and weather stations throughout the city.

While our data are slightly dated, we argue that it is compensated by its high quality. Figure 2 shows PM10 for the years of 2000-2015, with our period highlighted between the red vertical lines. Our focus of study does not show great variation from the rest of the span and can be thought of as representative for Mexico City in general, as it replicates the large seasonal variations. Air pollution in Mexico City has been an issue since the 1950s, and in the 90s was ranked the most polluted city in the world by the United Nations. The city started measuring air quality in the 1970s and since the 1990s started several comprehensive inter-agency government programs aimed to reduce pollution and educate the population (PROAIRE 2014). Still, while one could argue that air pollution levels and preferences about pollution may have not greatly changed since our period of study, we caution about generalizing our results to more recent years. 


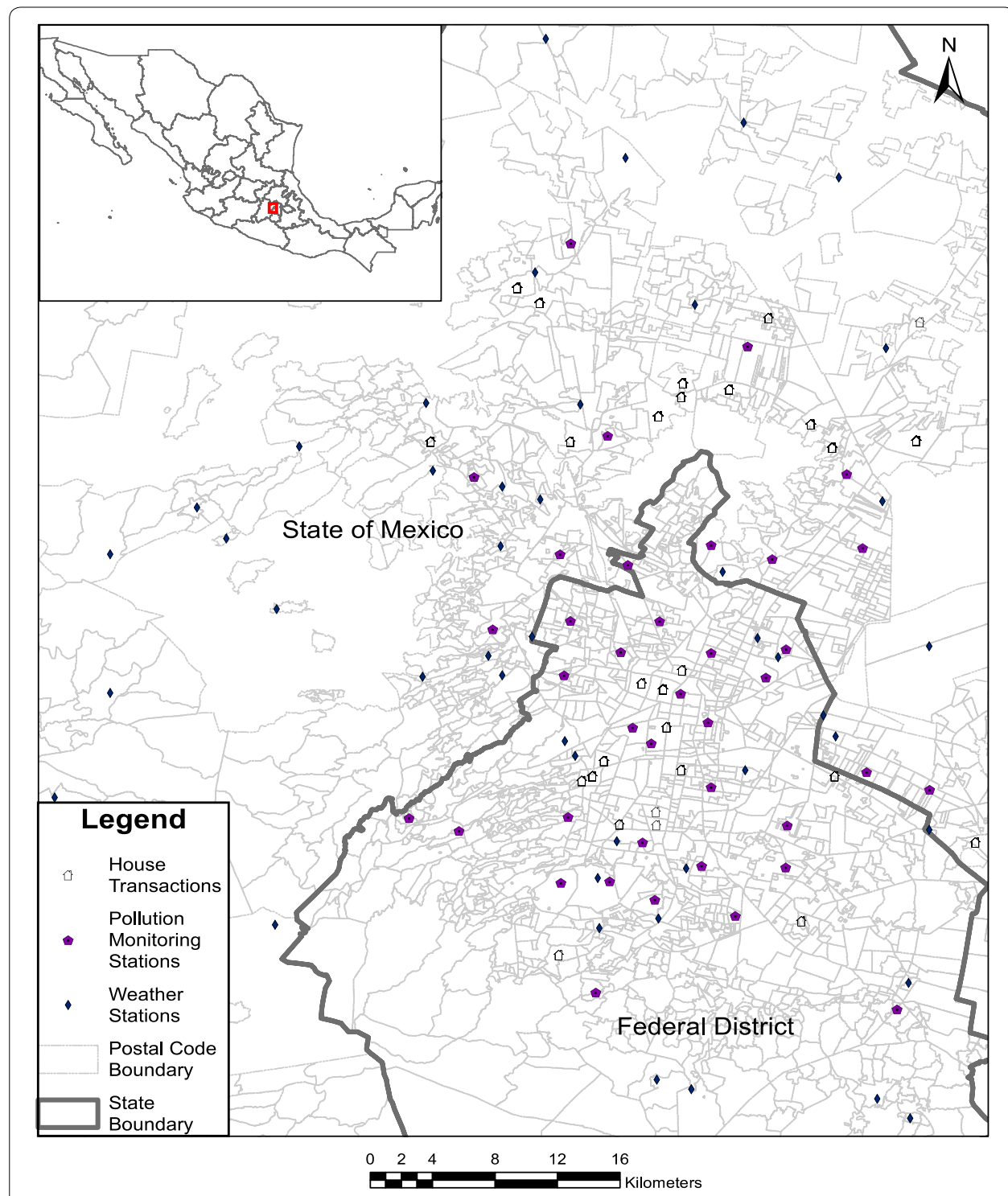

Fig. 1 Location of household transactions, pollution-monitoring stations, and weather stations in the study area. A house symbol may represent more than one transaction within the same postal code

Relationships between pollution, housing values, and wages may be influenced by other time-varying factors, making continuous and updated measurements of pollution's welfare effects an important policy tool.

Table 1 presents the relevant descriptive statistics for the variables used in our estimation. Combining all datasets, each house transaction contains variables on house attributes, socioeconomic characteristics of the household, and environmental conditions. More specifically, this includes the purchase price of the home, transaction date, average monthly mortgage payment, house and lot size, number of bedrooms, number of bathrooms, and number of parking spaces. For each home, we have location information and geographic coordinates of the zip code centroid. The socioeconomic variables include the combined total monthly income for all residents, along with age, marital status, 


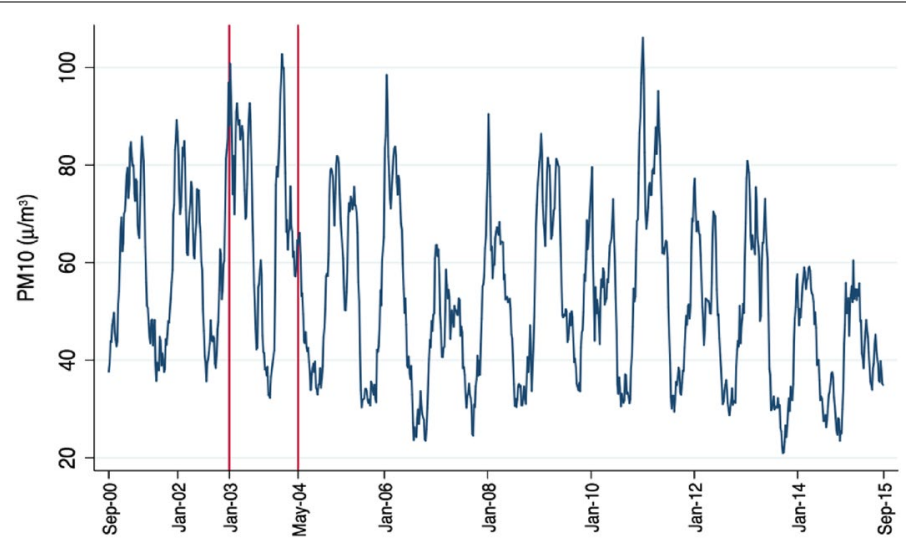

Fig. 2 PM10 Mexico City, 2000-2015

Table 1 Descriptive statistics

\begin{tabular}{|c|c|c|c|c|}
\hline & Mean & Std. dev. & Min & Max \\
\hline \multicolumn{5}{|l|}{ Housing } \\
\hline Housing value (US\$) $)^{a}$ & $48,748.77$ & $17,734.24$ & $20,380.84$ & $140,519.40$ \\
\hline Average monthly house payment (US\$) & 489.03 & 177.11 & 115.94 & 1717.25 \\
\hline Built size $\left(m^{2}\right)$ & 70.58 & 17.25 & 34.38 & 136.42 \\
\hline Lot size $\left(m^{2}\right)$ & 111.04 & 150.46 & 45.00 & 1038.00 \\
\hline Bedrooms & 2.64 & 0.59 & 1 & 3 \\
\hline Bathrooms & 1.26 & 0.43 & 1 & 2.5 \\
\hline Parking & 0.76 & 0.59 & 0 & 2 \\
\hline \multicolumn{5}{|l|}{ Socioeconomic variables } \\
\hline Household monthly income (US\$) $)^{\mathrm{a}}$ & 2816.05 & 1618.34 & 870.47 & $17,822.79$ \\
\hline Age (household head) & 37.73 & 8.55 & 21 & 61 \\
\hline Number of dependents & 1.18 & 1.21 & 0 & 6 \\
\hline Male (household head) & 0.63 & 0.48 & 0 & 1 \\
\hline Married & 0.55 & 0.49 & 0 & 1 \\
\hline College and above (household head) & 0.56 & 0.50 & 0 & 1 \\
\hline \multicolumn{5}{|l|}{ Environmental variables } \\
\hline $\operatorname{PM} 10\left(\mu \mathrm{g} / \mathrm{m}^{3}\right)^{\mathrm{c}}$ & 55.55 & 20.34 & 19.51 & 108.88 \\
\hline Rainfall $(\mathrm{mm})^{c}$ & 2.34 & 2.40 & 0 & 12.61 \\
\hline
\end{tabular}

a 2019 US\$

${ }^{\text {b }}$ Average mortgage length is approximately 25 years

c PM10 and rainfall are measured as the 24-h, 30-day average

number of dependents, and sex for the head of household. Finally, the PM10 concentration and precipitation make up the environmental variables.

\subsection{Housing and household variables}

The housing and socioeconomic data originally come from Sociedad Hipotecaria Federal (SHF) home mortgage originations. ${ }^{3}$ While each transaction included the neighborhood,

\footnotetext{
${ }^{3}$ For a detailed description of this data, see Fontenla \& Gonzalez (2009) and Gonzalez et al. (2013).
} 
municipality, and state, we also assigned each house to a zip code. Due to the lack of a public geographic information system (GIS)-based location for Mexico, each neighborhood was matched to a specific zip code using the Mexican Postal Service database (Sepomex 2010). GeoPostcodes then provided the geocoded latitude and longitude for the center (centroid) of each zip code. The top two sections of Table 1 provide the summary statistics of the housing and socioeconomic characteristics for each household.

All house transactions in our dataset come from new construction home sales. Mortgages for used home purchases were almost non-existent in Mexico during our period of study. In fact, government statistics show that there were no used home mortgages in 2002 or 2003 and only 62 in 2004 for all of Mexico (Conafovi 2002-2004). This is consistent with Rosen's theoretical framework, which excludes the resale housing market.

In addition, we are mainly capturing households that lie in the middle to higher end of the socioeconomic scale and are representative of Mexico City's middle class. This is the segment of society able to actively participate in the labor and housing markets and make choices to adjust for pollution levels. Lower income groups in Mexico City have limited access to mortgage markets and have a lower capacity to choose and negotiate in the labor market. That is, the poor have little ability to move and choose better jobs in response to air pollution.

\subsection{Environmental variables}

While there is no standard for the type of pollutant used for hedonic studies, Dunlap and York (2008) have shown that local visibility of air pollution relates directly to people's perceptions regarding its severity. Thus, we use PM10, as it is the most visible of measured pollutants. Our PM10 data summarized in Table 1 were obtained from the National Ecology Institute (INE) which validates and disseminates air pollution data from air quality-monitoring stations (AQMS). During our study, there were 15 AQMS recording data on an hourly basis for Mexico City.

We created a PM10 measurement related to each house transaction that best represents the most influential time during the home buying process. Consistent with the hedonic models, we expect that as home buyers visit multiple sites in their search the differences in pollution levels will be capitalized in the final negotiated house price. According to SHF mortgage officers, there is approximately a 6-month process to purchase a residence in Mexico City. This includes the search, credit application and approval, and additional title work. Most of the house hunting and site visits occurs 6 months prior to closing and represents the time when air pollution would have its greatest impact on buying decisions. Therefore, for each household, we approximated the PM10 exposure encountered by the home buyer as a 30-day pollution average, 6 months prior to the given closing date. While buyers may have a general idea of average overall pollution levels within an area, the time of visit should form their final perceptions, and thus influence their pollution assessment. As falsification checks, we present alternative specifications with 2-10-month lags. Further, we explore the impacts of different windows of 
pollution and rainfall averages (45, 60, and 365 days), and using standardized pollution and environmental variables with historical trends removed. ${ }^{4}$

Using the 30-day window, the pollution measure for a house sale that closed on 20 December 2003 would be the 30-day pollution average around 20 June 2003, starting on 5 June 2003 and ending on 5 July 2003. Due to the temporal variation in home sales, this provides a unique PM10 exposure for each housing transaction, even if they are located in the same zip code. ${ }^{5}$ The daily concentrations of PM10 were computed as the 24-h average PM10. Next, to create our 30-day PM10 averages, we obtained, from INE (2010), the GIS coordinates of all the AQMS in Mexico City. We assigned to each postal code all the AQMS within a 15- $\mathrm{km}$ radius from the postal code centroid. We then created the inverse weight distance (IWD) as follows:

$$
\phi_{z}=\frac{\sum_{m} \frac{\phi_{m}}{d_{m}^{2}}}{\sum_{m} \frac{1}{d_{m}^{2}}}
$$

where $\phi_{z}$ is the daily PM10 measure on postal code $z, \phi_{m}$ is the 24-h average PM10 concentration in AQMS $m$, and $d_{m}$ is the distance between the air quality-monitoring station $m$ and the centroid of the postal code $z$. The IWD method has been widely used in the literature and performs better in obtaining estimates of the wage or house price-pollution gradient relative to alternatives such as Thiessen polygons (Anselin and Le Gallo 2006). Finally, we computed the 30-day average PM10 measure for each housing unit.

Rainfall is measured as the 24-h accumulated precipitation in millimeters $(\mathrm{mm})$. While the AQMS in Mexico City also record rainfall data, they are sparse with widespread missing observations. To correct this problem, we used rainfall data from the weather monitoring stations (WMS) used by the National Water Commission (CONAGUA) in Mexico City. We used the ERICIIIv2 to get daily rainfall and the GIS location for each of CONAGUA's WMS. As in the case of PM10, we assigned to each postal code all the WMS within a 10-km radius from the postal code centroid. This left us with 39 WMS that are matched to at least one postal code. Finally, we used the same IWD method to compute the 30-day average rainfall measures for each time lag around the closing date.

\section{Empirical estimation}

As discussed above, the value of local amenities in an area, such as clean air, will be reflected implicitly in both the housing and wage markets. Therefore, the impact that air pollution concentrations has on housing values and wages can be estimated by the following equations:

$$
\begin{aligned}
& \ln \left(\text { housevalue }_{i j k}\right)=\alpha_{0}+\alpha_{1} \ln \left(\mathrm{PM} 10_{j k}\right)+\alpha_{2} Y_{i}+\alpha_{3} X_{j}+\psi_{k}+\delta_{m}+\varepsilon_{1 i j k}, \\
& \ln \left(\text { wage }_{i k}\right)=\beta_{0}+\beta_{1} \ln \left(\mathrm{PM} 10_{j k}\right)+\beta_{2} Y_{i}+\psi_{k}+\delta_{m}+\varepsilon_{2 i k},
\end{aligned}
$$

where $i, j$, and $k$ represent the individual household, housing unit, and zip code, respectively. The vector $X_{j}$ contains the physical characteristics of the house, and vector $Y_{i}$

\footnotetext{
${ }^{4}$ Results remain qualitatively the same. Robustness and falsification tests using different moving average windows, multiple time lags, and standardized variables are available upon request from the authors.

${ }^{5}$ Houses will only have the same pollution readings if they are sold on the same day in the same postal code.
} 


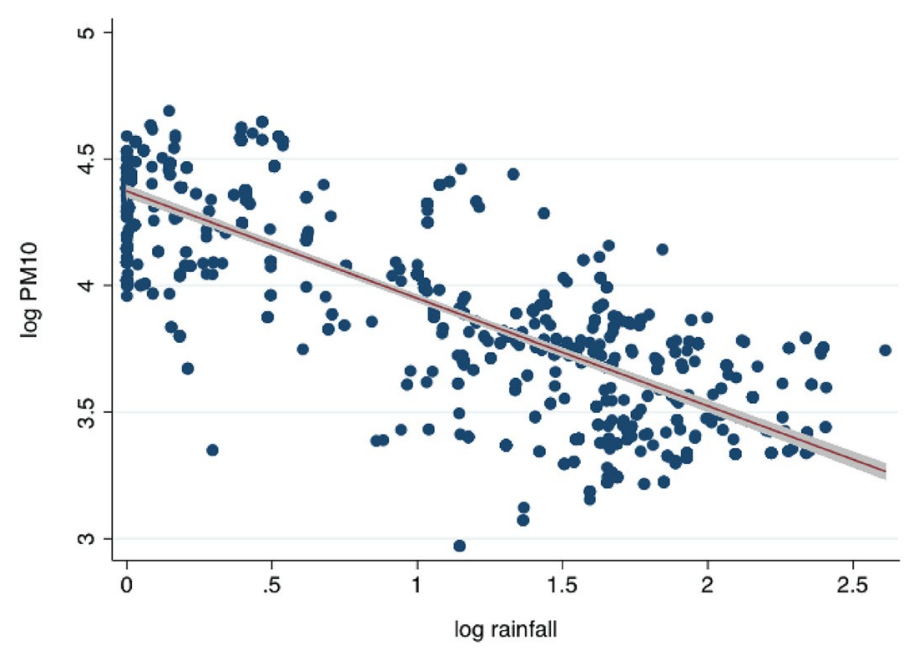

Fig. 3 PM10 and rainfall

contains the socioeconomic variables of the household purchasing the property, as detailed in the descriptive statistics of Table 1. The socioeconomic variables used in the house value model serve as a proxy for neighborhood characteristics, similar to previous studies (Zabel 2004; Fontenla and Gonzalez 2009). Finally, $\psi_{k}$ are spatial fixed effects, $\delta_{m}$ are monthly dummy variables, and $\varepsilon$ are the equation specific error terms. Spatial fixed effects at the zip code level help account for time in varying effects and reduce spatial autocorrelation inherent in hedonic analysis. They also help account for variation in other locational attributes such as traffic and distance to the city center, reducing omitted variable bias. The monthly dummies help account for any seasonality in the housing, wage, and environmental variables. We use the natural logarithm of our main variables to reduce skewness and to aid in interpreting our coefficients as elasticities. ${ }^{6}$

Independent estimation of Eqs. (6) and (7) may be biased due to missing variables and endogeneity issues. A better econometric technique that takes these concerns into account is a three-stage least squares (3SLS) instrumental variables approach, where we also estimate PM10 in the form:

$$
\ln \left(\mathrm{PM}_{j k}\right)=\gamma_{0}+\gamma_{1} \ln \left(\text { rainfall }_{j k}\right)+\psi_{k}+\delta_{m}+\varepsilon_{3 j k},
$$

with rainfall as the instrument, $\psi_{k}$ as zip code fixed effects, and $\delta_{m}$ monthly dummies. In addition, the 3SLS model incorporates the correlations of the disturbances across the wage and housing price equations, by not assuming the covariance of the error terms to be zero. This method thus considers the three equations above as a simultaneous system of equations. $^{7}$

\subsection{Instrumental variable}

Rainfall effectively removes suspended particulate matter from the air (Ruijgrok and Romer 1993). Figure 3 shows a strong negative relationship between rainfall and PM10 in our data, with a correlation coefficient of -0.80 . Additional evidence of this negative

\footnotetext{
${ }^{6}$ We also run the regressions in levels, and the results remain largely unchanged.

7 OLS and 2SLS estimations are shown in the appendix for robustness purposes.
} 


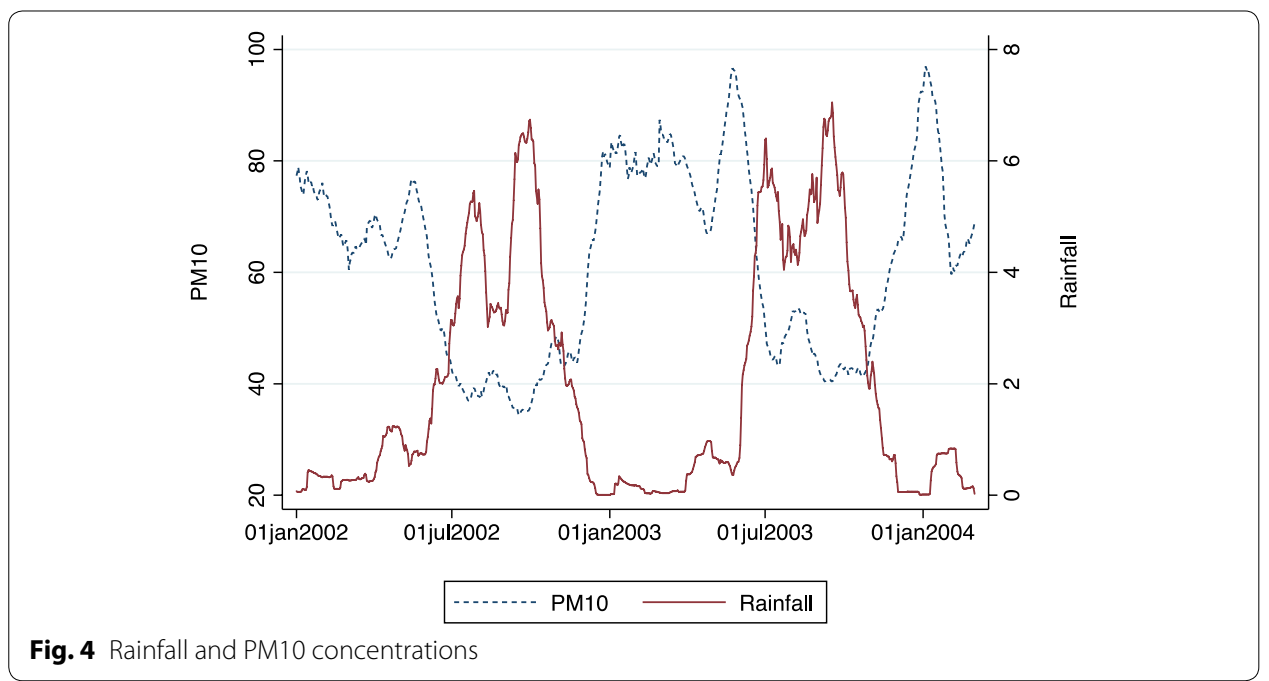

relationship is shown in Fig. 4. It shows a strong negative relationship between the overall 30-day moving average PM10 and rainfall from January 2003 to February 2004 for all of Mexico City. This figure also illustrates the strong negative correlation, where pollution decreases in the rainy summer season and increases in the dry winter months.

A potential shortfall occurs if rainfall is believed to directly impact housing prices and wages, violating the validity of our instrument. Rain could be considered an amenity in itself, especially if its variation is large. This could be true in country-wide studies comparing cities across large geographic distances, with their correspondingly large weather contrasts that may affect a household's location choice. However, this concern is minimized in our case, as our study focuses on a single city. While there is variation in rain across zip codes, it should not be large enough to directly impact the choice of where to work and live within Mexico City. Further, in the event that rain acts as an amenity in itself, it would work in the opposite direction of its effect on pollution. High rain would be considered a negative amenity in an urban setting, whereas it improves air quality. If this is the case, our estimates would provide a lower bound of the effects of air pollution on housing prices and incomes.

Another potential concern is that rainfall variations could affect wages through agricultural yields. However, this is not a problem in our paper as there is no agriculture in our area of study. Therefore, localized rain patterns cannot directly affect local wages via agriculture.

Finally, all our regressions include fixed effects at the zip code level and additional controls to alleviate relevance and validity concerns. We also perform formal relevance and validity tests in the 2SLS specification shown in the appendix. To be able to perform overidentification tests, we use rainfall lagged by 1 month as a second instrument, in addition to contemporary rainfall. Both Kleibergen-Paap and the Hansen J statistics support the relevance and validity of our instruments, respectively.

\section{Results and discussion}

Table 2 presents the results for the 3SLS model, where we simultaneously evaluate the system of three Eqs. (6)-(8). OLS and 2SLS specifications are included in the appendix for robustness purposes. 
Table 2 3SLS-PM10 effects on housing prices and wages at 6-month lag

\begin{tabular}{llll}
\hline & House price & Wage & PM10 \\
\hline PM10 & $-0.301(0.0672)^{* * *}$ & $1.604(0.122)^{* * *}$ & \\
Wage & $0.216(0.0788)^{* *}$ & & $-0.162(0.0119)^{* * *}$ \\
Rainfall & & & 0.860 \\
R-squared & 0.822 & 0.354 & \\
Observations & 1381 & & \\
\hline
\end{tabular}

Standard errors in parentheses

Standard errors are clustered at the zip code level

All regressions include all controls and zip code fixed effects

${ }^{*} p<0.05,{ }^{* *} p<0.01,{ }^{* * *} p<0.001$

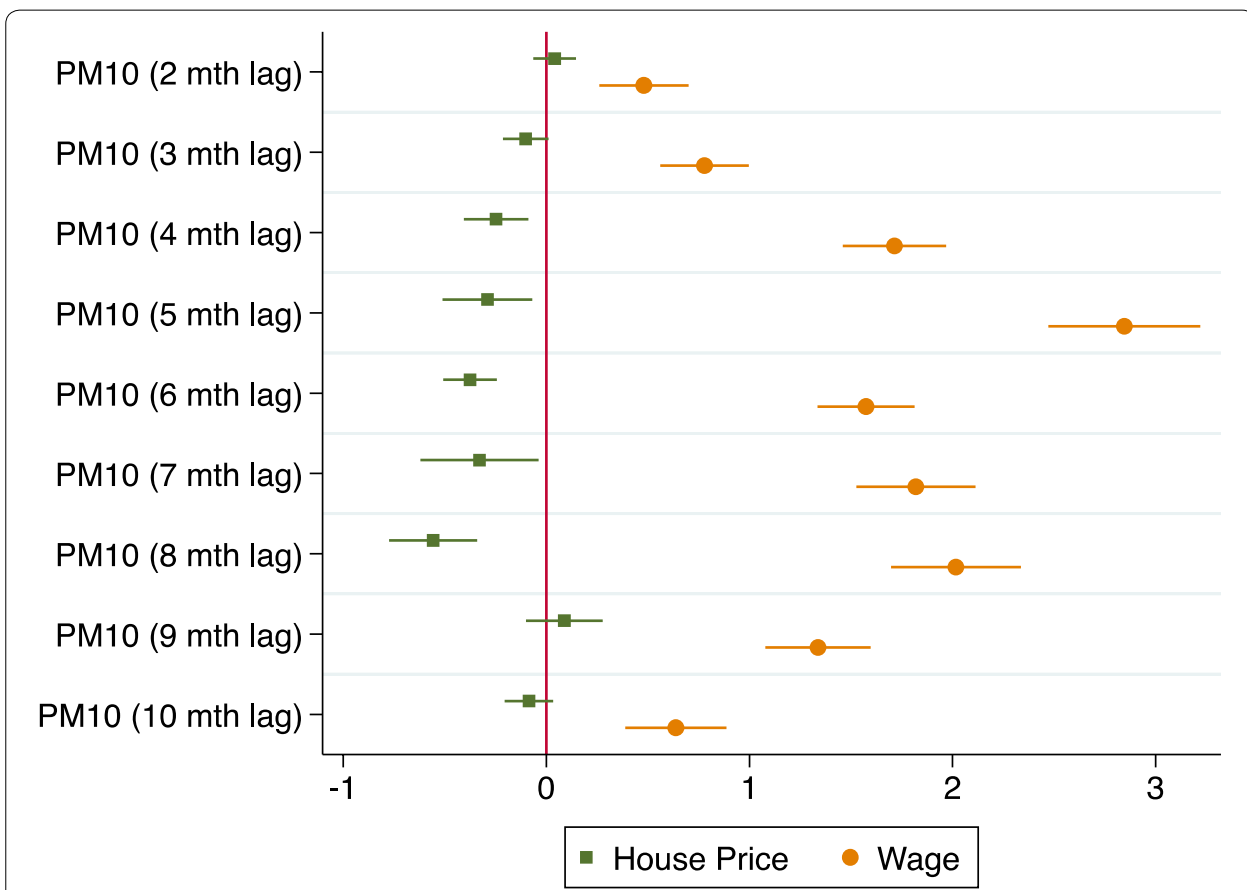

Fig. 5 Coefficient estimates with 95\% confidence intervals of PM10 for house price and wage equations using 3SLS and 30-day averages for multiple time lags

The results for PM10 show statistically significant elasticities of -0.301 and 1.604 for house price and wage, respectively. That is, housing prices are lower and wages are higher with increases in air pollution. This is the main result of our paper, which is consistent with our main hypothesis as developed in the theoretical section. In addition, in line with scientific evidence, our rainfall instrument has a large negative effect on air pollution.

Figure 5 depicts the effect of PM10 on housing prices and wages for 2-10-month lags relative to the final purchasing date, as robustness and falsification tests. The graph shows a pattern where the coefficients move closer to zero as they move away from the 6-month lag in either direction. This supports our hypothesis that the time the household visits the property influences their assessment of air pollution levels, which in turn affect housing prices and wages. 


\subsection{Compensating differential}

We use the results on PM10 from the previous section to calculate the compensating differential, or full implicit price of air pollution. Since our estimates of the effects of PM10 on house values and wages represent elasticities, we adjust our empirical calculation of the welfare measure, Eq. (4). Here, we follow Bayer et al. (2009) as in:

$$
\hat{\varphi}^{*}=-\frac{\overline{h p}}{\overline{P M 10}} \hat{\alpha}_{1}+\frac{\bar{w}}{\overline{P M 10}} \hat{\beta}_{1},
$$

where bars over variables denote our sample averages, and hats indicate the estimated parameters from Table $2 . \overline{h p}$ denotes the average monthly house payment. ${ }^{8}$ To compute the effect of air pollution on housing prices, we multiply the estimated parameter of 0.301 by the mean monthly house payment of US $\$ 489.03$, and then divide it by the average PM10 concentration of $55.55 \mu \mathrm{g} / \mathrm{m}^{3}$. This gives an estimate of US\$ 2.65. Similarly, to compute the effect of air pollution on wages, we multiply the estimated parameter 1.604, by the sample mean monthly wage of US $\$ 2816.05$, and divided by the average PM10 concentration to get US\$ 81.31 per month. Thus, the total compensating differential is US\$ 83.96 , or $2.98 \%$ of average income.

Multiplied by 12 to get an annual total, the estimated compensating differential is US\$ 1007.54 (95\% confidence interval of US\$ 847.61-1167.50 and $p$ value $<0.01$ ) per year to endure an increase of air pollution by $1 \mu \mathrm{g} / \mathrm{m}^{3}$, or around US $\$ 10,075.57$ for a $10 \mu \mathrm{g} / \mathrm{m}^{3}$ increase. This is probably more relevant as we expect that individuals consider air pollution based on their visual assessment. A $1 \mu \mathrm{g} / \mathrm{m}^{3}$ change might be difficult to ascertain, while $10 \mu \mathrm{g} / \mathrm{m}^{3}$ will be more noticeable. Further, Mexico City can show swings in air pollution of almost $100 \mu \mathrm{g} / \mathrm{m}^{3}$, suggesting significant variations across the city.

We caution about extending these estimates beyond the geographic area of our study, as is the case with any hedonic study. In addition, comparing our results with other studies should be done with prudence, as different data, methodologies, and outcome variables may render results difficult to compare. In addition, bias due to omitted variables in both the housing and wage equations is always a concern.

Our results suggest that most of the compensating differential is capitalized in the wage market. These high estimates can be due to the fact that our households lie in the middle to higher end of the socioeconomic scale, and are thus more capable to respond to localized amenities. In addition, our data are originated from actual mortgages, for which working is a requirement. That is, we do not have information on households that do not work, nor own a home. This can bias our results upward, as we are not able to correct for non-workers and non-owners, as done, for example, with two-stage Heckman selection models.

On the other hand, our data are high quality in that it contains actual, individual housing transactions and wages, rather than relying on city averages. Further, our intra-city analysis reduces biases that may occur due to migration and information costs associated with distances between cities.

\footnotetext{
${ }^{8} h$, the house value in our data is the full price of the house, whose average is US\$ 48,749. However, we need to calculate the monthly cost of housing to include it into the monthly compensating differential. Since our data include the actual monthly mortgage payment for each household, we use that. Similarly, Lavín et al. (2011) use monthly rental costs for their study on Chile. Bayer et al. (2009) use the average share of income that a typical US household spends on housing (0.2). Huang and Lanz (2018) assume that a housing unit lasts in China lasts 70 years and divide the house value by 70 to get to the yearly cost of housing.
} 


\section{Conclusion}

Traditional hedonic models calculate the compensating differentials for local amenities based on the implicit price for that good found in the variability of house prices. However, as Roback (1982) shows, a potential equilibrium exists between house prices, wages, and local amenities. As individuals decide where to live, they maximize utility balancing living costs, income, and goods provided by the area.

In this paper, we analyze the impact that air pollution has on house prices and wages. We use data from Mexico City that includes actual transacted housing prices, physical characteristics of the housing unit, socioeconomic information from each household, daily PM10 concentrations, and daily rainfall. This allows us to gain an understanding of how people in Mexico City value clean air. Using a three-stage least squares model, we show the impact that air pollution has on house prices and wages. We concentrate our analysis to within-city variation in a large, highly polluted city in a developing country.

Our results provide useful information for policy makers. When deciding on regulations, these estimates can be included in benefit-cost analyses, representing actual valuation of clean air by its citizens. If estimates under-represent the value of clean air, then this discourages government policy aimed at mitigating pollution, with all its health and quality of life implications.

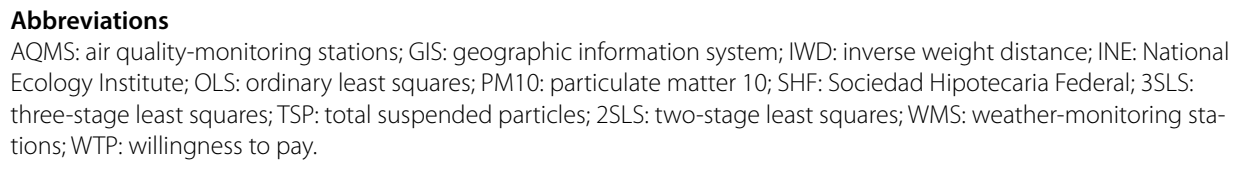

Acknowledgements

We would like to thank conference participants at the International Economic Association in Mexico City (IEA 2017), seminar participants at the Universidad Nacional del Sur, the University of New Mexico, Kira Villa, Andrew Goodkind, Bob Berrens, and two anonymous referees for helpful suggestions that greatly improved the manuscript.

\section{Authors' contributions}

MF and MBG conducted and interpreted the analyses regarding the hedonic valuation of pollution using housing prices and wages. MBG compiled the final dataset. FG generated the pollution, environmental, and housing data using geographic information systems tools. All the authors were major contributors in writing the final manuscript. All authors read and approved the final manuscript.

Funding

The authors declare there was no funding for this research.

\section{Availability of data and materials}

Portions of the datasets generated and/or analyzed during the current study are publicly available from the National Ecology Institute (INE, https://sinaica.inecc.gob.mx/scica/) and National Water Commission (CONAGUA, https://www. gob.mx/conagua) of Mexico. The remaining data are not publicly available due to privacy concerns relating to personal information. The dataset is available upon request from the authors in a de-identified format.

Competing interests

The authors declare that they have no competing interests.

\section{Author details}

${ }^{1}$ Department of Economics, University of New Mexico, Albuquerque, NM 87131, USA. ${ }^{2}$ Department of Economics and Intl. Business, Sam Houston State University, Huntsville, TX 77341, USA.

\section{Appendix}

\section{A. Ordinary least squares}

Below are the estimations of our models given by Eqs. (6) and (7) using ordinary least squares (OLS). As there is an endogeneity problem, we expect these estimates to be biased towards zero.

See Tables 3, 4 . 
Table 3 Estimation results for house price regressions using ordinary least squares (OLS)

\begin{tabular}{|c|c|c|c|c|c|c|c|}
\hline & $\begin{array}{l}\text { (1) House } \\
\text { price }\end{array}$ & $\begin{array}{l}\text { (2) House } \\
\text { price }\end{array}$ & $\begin{array}{l}\text { (3) House } \\
\text { price }\end{array}$ & $\begin{array}{l}\text { (4) House } \\
\text { price }\end{array}$ & $\begin{array}{l}\text { (5) House } \\
\text { price }\end{array}$ & $\begin{array}{l}\text { (6) House } \\
\text { price }\end{array}$ & $\begin{array}{l}\text { (7) House } \\
\text { price }\end{array}$ \\
\hline $\begin{array}{l}\text { PM10 (10- } \\
\text { month lag) }\end{array}$ & $\begin{array}{l}0.0170 \\
\quad(0.0299)\end{array}$ & & & & & & \\
\hline $\begin{array}{l}\text { PM10 } \\
\text { (9-month } \\
\text { lag) }\end{array}$ & & $\begin{array}{l}0.0295 \\
(0.0269)\end{array}$ & & & & & \\
\hline $\begin{array}{l}\text { PM10 } \\
\text { (8-month } \\
\text { lag) }\end{array}$ & & & $\begin{array}{l}0.00,691 \\
(0.0276)\end{array}$ & & & & \\
\hline $\begin{array}{l}\text { PM10 } \\
\text { (7-month } \\
\text { lag) }\end{array}$ & & & & $\begin{array}{l}0.0938 \\
(0.0275)^{* * * *}\end{array}$ & & & \\
\hline $\begin{array}{l}\text { PM10 } \\
\text { (6-month } \\
\text { lag) }\end{array}$ & & & & & $\begin{array}{r}-0.00523 \\
(0.0241)\end{array}$ & & \\
\hline $\begin{array}{l}\text { PM10 } \\
\text { (5-month } \\
\text { lag) }\end{array}$ & & & & & & $\begin{array}{l}0.0202 \\
(0.0347)\end{array}$ & \\
\hline $\begin{array}{l}\text { PM10 } \\
\text { (4-month } \\
\text { lag) }\end{array}$ & & & & & & & $\begin{array}{l}-0.0705 \\
(0.0286)^{*}\end{array}$ \\
\hline Wage & $\begin{array}{l}0.127 \\
\quad(0.0161)^{* * * *}\end{array}$ & $\begin{array}{l}0.129 \\
(0.0161)^{* * *}\end{array}$ & $\begin{array}{l}0.129 \\
\quad(0.0160)^{* * * *}\end{array}$ & $\begin{array}{l}0.125 \\
\quad(0.0159)^{* * * *}\end{array}$ & $\begin{array}{l}0.126 \\
\quad(0.0161)^{* * * *}\end{array}$ & $\begin{array}{l}0.121 \\
\quad(0.0159)^{* * * *}\end{array}$ & $\begin{array}{l}0.118 \\
\quad(0.0153)^{* * *}\end{array}$ \\
\hline R-squared & 0.840 & 0.842 & 0.842 & 0.844 & 0.843 & 0.842 & 0.842 \\
\hline Observations & 1384 & 1394 & 1402 & 1405 & 1387 & 1398 & 1438 \\
\hline
\end{tabular}

Standard errors in parentheses

Each column represents a separate regression of the house price equation (Eq. 8) for different lags. Standard errors are clustered at the zip code level. All regressions include all the controls and zip code fixed effects

${ }^{*} p<0.05,{ }^{* *} p<0.01,{ }^{* * *} p<0.001$

Table 4 Estimation results for wage regressions using ordinary least squares (OLS)

\begin{tabular}{|c|c|c|c|c|c|c|c|}
\hline & (1) Wage & (2) Wage & (3) Wage & (4) Wage & (5) Wage & (6) Wage & (7) Wage \\
\hline $\begin{array}{l}\text { PM10 (10- } \\
\text { month } \\
\text { lag) }\end{array}$ & $\begin{array}{l}0.159 \\
\quad(0.0506)^{* *}\end{array}$ & & & & & & \\
\hline $\begin{array}{l}\text { PM10 } \\
\text { (9-month } \\
\text { lag) }\end{array}$ & & $\begin{array}{l}0.386 \\
\quad(0.0578)^{* * *}\end{array}$ & & & & & \\
\hline $\begin{array}{l}\text { PM10 } \\
\text { (8-month } \\
\text { lag) }\end{array}$ & & & $\begin{array}{l}0.368 \\
\quad(0.0667)^{* * * *}\end{array}$ & & & & \\
\hline $\begin{array}{l}\text { PM10 } \\
\text { (7-month } \\
\text { lag) }\end{array}$ & & & & $\begin{array}{l}0.222 \\
\quad(0.0665)^{* * *}\end{array}$ & & & \\
\hline $\begin{array}{l}\text { PM10 } \\
\text { (6-month } \\
\text { lag) }\end{array}$ & & & & & $\begin{array}{l}0.446 \\
\quad(0.0660)^{* * *}\end{array}$ & & \\
\hline $\begin{array}{l}\text { PM10 } \\
\quad \text { (5-month } \\
\text { lag) }\end{array}$ & & & & & & $\begin{array}{l}0.307 \\
\quad(0.0849)^{* * *}\end{array}$ & \\
\hline $\begin{array}{l}\text { PM10 } \\
\text { (4-month } \\
\text { lag) }\end{array}$ & & & & & & & $\begin{array}{l}0.450 \\
\quad(0.0737)^{* * *}\end{array}$ \\
\hline R-squared & 0.474 & 0.487 & 0.482 & 0.474 & 0.489 & 0.467 & 0.470 \\
\hline Observations & 1384 & 1394 & 1402 & 1405 & 1387 & 1398 & 1438 \\
\hline
\end{tabular}

Standard errors in parentheses

Each column represents a separate regression of the wage equation (Eq. 9) for different lags

Standard errors are clustered at the zip code level. All regressions include all the controls and zip code fixed effects

${ }^{*} p<0.05,{ }^{* *} p<0.01, * * * 0<0.001$ 
Table 5 2SLS-PM10 effects on housing prices and wages at 6-month lag

\begin{tabular}{lllll}
\hline & (1) PM10 & (2) House price & (3) PM10 & (4) Wage \\
\hline Rainfall 6-month lag & $-0.189(0.0145)^{* * *}$ & & $-0.176(0.0136)^{* * *}$ & \\
Rainfall 7-month lag & $0.0577(0.0253)^{*}$ & & $0.108(0.0259)^{* * *}$ & \\
Wage & $0.0304(0.0116)^{* *}$ & $0.130(0.0163)^{* * *}$ & & \\
PM10 & & $-0.133(0.0612)^{* *}$ & & $0.534(0.156)^{* * *}$ \\
K-P statistic & & 172.8 & & 168.9 \\
K-P F-statistic & & 111.7 & & 111.5 \\
Hansen J statistic & & 0.102 & & 0.186 \\
Hansen J p value & & 0.749 & 0.667 \\
R-squared & 0.882 & 0.416 & 0.864 & 0.0889 \\
Observations & 1381 & 1381 & 1381 & 1381 \\
\hline
\end{tabular}

Standard errors in parentheses

Columns (1) and (3) represent the first stage results and (2) and (4) are the second stage results of the 2SLS estimation for the house and wage equations at the 6-month lag, respectively. Standard errors are clustered at the zip code level. All regressions include all controls and zip code fixed effects. K-P Stat: Kleibergen-Paap LM statistic. K-P F-stat: KleibergenPaap Wald F-statistic

${ }^{*} p<0.05,{ }^{* *} p<0.01,{ }^{* * *} p<0.001$

\section{B. Two-stage least squares}

2SLS housing and wage equations are calculated independently of each other. That is, 2SLS ignores potential endogeneity between the housing and labor markets, de facto assuming the covariance of the error terms to be zero. To be able to perform overidentification tests, we use rainfall lagged by 1 month as a second instrument, in addition to contemporary rainfall. Both Kleibergen-Paap and the Hansen J statistics support the relevance and validity of our instruments, respectively.

See Table 5.

Received: 7 March 2019 Accepted: 18 October 2019

Published online: 04 November 2019

\section{References}

Anselin L, Le Gallo J (2006) Interpolation of air quality measures in hedonic house price models: spatial aspects. Spat Econ Anal 1(1):31-52

Barmpadimos I, Hueglin C, Keller J, Henne S, Prévôt A (2011) Influence of meteorology on pm 10 trends and variability in Switzerland from 1991 to 2008. Atmos Chem Phys 11(4):1813-1835

Bayer P, Keohane N, Timmins C (2009) Migration and hedonic valuation: the case of air quality. J Environ Econ Manag 58(1):1-14

Berger MC, Blomquist GC, Peter KS (2008) Compensating differentials in emerging labor and housing markets: estimates of quality of life in Russian cities. J Urban Econ 63(1):25-55

Carriazo F, Gomez-Mahecha JA (2018) The demand for air quality: evidence from the housing market in Bogotá, colombia. Environ Dev Econ 23(2):121-138

Chakraborti L, Heres D, Hernandez D (2019) Are land values related to ambient air pollution levels? Hedonic evidence from Mexico City. Environ Dev Econ. 24:252-270

Conafovi (2002-2004), Estadistica de vivienda, Technical report, Comision Nacional de Fomento a la Vivienda, Mexico

Dunlap RE, York R (2008) The globalization of environmental concern and the limits of the post materialist values explanation: evidence from four multinational surveys. Sociol Q 49(3):529-563

Filippini M, Martinez-Cruz AL (2016) Impact of environmental and social attitudes, and family concerns on willingness to pay for improved air quality: a contingent valuation application in Mexico city. Latin Am Econ Rev 25(1):7

Fontenla M, Gonzalez F (2009) Housing demand in Mexico. J Hous Econ 18(1):1-12

Gonzalez F, Leipnik M, Mazumder D (2013) How much are urban residents in Mexico willing to pay for cleaner air? Environ Dev Econ 18(03):354-379

Huang X, Lanz B (2018) The value of air quality in chinese cities: evidence from labor and property market outcomes. Environ Resour Econ 71(4):849-874 
INE (2010) Sistema nacional de informacion de la calidad del aire: Informacion sobre las redes, Technical report. Instituto Nacional de Ecologia, Mexico

Izon GM, Hand MS, Fontenla M, Berrens RP (2010) The economic value of protecting inventoried roadless areas: a spatial hedonic price study in new mexico. Contemp Econ Policy 28(4):537-553

Lavín FV, Dresdner J, Aguilar R (2011) The value of air quality and crime in Chile: a hedonic wage approach. Environ Dev Econ 16(3):329-355

Li MM, Brown HJ (1980) Micro-neighborhood externalities and hedonic housing prices. Land Econ 56(2):125-141

Palmquist RB (1982) Measuring environmental effects on property values without hedonic regressions. J Urban Econ 11(3):333-347

PROAIRE (2014) Programa para mejorar la calidad del aire de la zona metropolitana del valle de mexico 2011-2020, Technical report. Comision Ambiental Metropolitana, Mexico

Roback J (1982) Wages, rents, and the quality of life. J Polit Econ 90:1257-1278

Rodriguez-Sanchez II (2014) Do Mexicans care about air pollution? Latin Am Econ Rev 23(1):9

Ruijgrok W, Römer FG (1993) Aspects of wet, acidifying deposition in Arnhem: source regions, correlations and trends (1984-1991). Atmos Environ. 27(1):637-653

Sepomex (2010) Consulta de codigos postales, Technical report. Servicio Postal Mexicano, Mexico

Smith VK, Huang J-C (1995) Can markets value air quality? A meta-analysis of hedonic property value models. J Polit Econ. 103:209-227

WHO (2014) Ambient (outdoor) air pollution in cities database 2014, Technical report. World Health Organization, Geneva Zabel JE (2004) The demand for housing services. J Hous Econ 13(1):16-35

Zabel JE, Kiel KA (2000) Estimating the demand for air quality in four US cities. Land Econ 76(2):174-194

\section{Publisher's Note}

Springer Nature remains neutral with regard to jurisdictional claims in published maps and institutional affiliations.

\section{Submit your manuscript to a SpringerOpen ${ }^{\circ}$ journal and benefit from:}

- Convenient online submission

- Rigorous peer review

- Open access: articles freely available online

High visibility within the field

- Retaining the copyright to your article

Submit your next manuscript at $\gg$ springeropen.com 